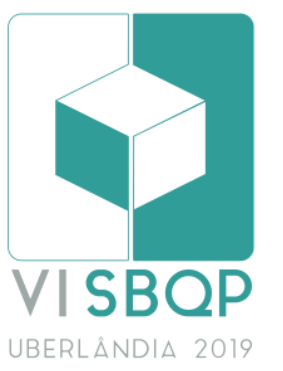

\title{
USO DO SOLO E PADRÕES DE VIAGEM: UMA ANÁLISE METODOLÓGICA BASEADA EM ESTUDOS DE CASO
}

\author{
GARREFA, Fernando \\ Universidade Federal de Uberlândia, e-mail: fgarrefa@ufu.br \\ BETETE, Beatriz \\ Universidade Federal de Uberlândia, e-mail: beatrizbetette@gmail.com \\ DENADAE, Isabella \\ Universidade Federal de Uberlândia, e-mail: isabelladenadae@gmail.com \\ ANGSTMAM, Juliana \\ Universidade Federal de Uberlândia, e-mail: juliana.cervi@yahoo.com.br \\ ELIAS, Julia \\ Universidade Federal de Uberlândia, e-mail: juliattavares19@gmail.com \\ GUIMARÃES, Nayara \\ Universidade Federal de Uberlândia, e-mail: nayaraguimaraes29@gmail.com
}

\begin{abstract}
RESUMO
O trabalho busca identificar e analisar metodologias empregadas para análise dos padrões de viagem a partir do uso do solo, com especial enfoque nas viagens motivadas com finalidade de compras. O artigo delineia três estudos de caso em diferentes cidades a fim de auxiliar na montagem de metodologia própria de análise a ser empregada em cidades médias. $\bigcirc$ trabalho traz ainda os resultados preliminares do piloto aplicado ao caso de Uberlândia-MG. Análises espaciais baseadas em big data podem contribuir significativamente para a elaboração de políticas públicas e legislação de uso do solo urbano visando ao desenvolvimento mais sustentável dessas cidades.
\end{abstract}

Palavras-chave: Mobilidade Urbana, Padrões de Viagem, Uso do Solo, Comércio

\begin{abstract}
This paper aims to identify and study some methodologies used to annalise the travel behaviour from land usage, primarily focusing on purchase-motivated travels. The article points out three case studies in different cities aiming to contribute to the setup of a specific methodology destined to study medium-sized towns. Additionally, this paper counts on a preliminary analysis from a pilot carried out in the city of Uberlândia-Brazil. Spatial analysis based on Big Data can significantly contribute to the development of public policies and land usage laws seeking to achieve sustainable development of these cities
\end{abstract}

Keywords: Urban Mobility, Travel Behaviour, Land Use, Commerce

\section{INTRODUÇÃO}

Extensa literatura tem demonstrado as relações do uso do solo urbano com os padrões de viagem. Dentre os usos do solo urbano, destacam-se aqueles ligados às atividades terciários como grandes motivadores das viagens intraurbanas. Por outro lado, o crescimento fragmentado das cidades no Brasil e em outras partes do mundo, consagrou o automóvel como meio preferencial de transporte. O resultado, em que pese investimentos em outros modais de

GARREFA, F.; BETETE, B.; DENADAE, I.; ANGSTMAM, J.; ELIAS, J.; GUIMARÃES, N. Uso do solo e padrões de viagem: uma análise metodológica baseada em estudos de caso. In: SIMPÓSIO BRASILEIRO DE QUALIDADE DO PROJETO NO AMBIENTE CONSTRUÍDO, 6., 2019, Uberlândia. Anais... Uberlândia: PPGAU/FAUeD/UFU, 2019. p. 1636-1645. DOI https://doi.org/10.14393/sbqp19148. 
transporte, pode ser visualizado nos congestionamentos diários com grande desperdício energético acompanhado também pelo aumento na polvição ambiental e no stress cotidiano. A partir dessas constatações, esse trabalho busca identificar metodologias para análise dos padrões de viagem a partir dos usos do solo urbano comerciais. Se centra na análise de estudos de caso já empreendidos, com a finalidade de montar metodologia de análise própria que em fase posterior servirá para análise em cidades médias brasileiras, de forma a subsidiar políticas públicas e insumos para elaboração de legislação urbanística que possa mitigar os efeitos de tais padrões de viagem. As análises contidas nesse trabalho partiram da identificação de 3 trabalhos recentes, com especial uso de análises espaciais a partir de ferramentas computacionais e com uso de big data.

\section{CASOS ESTUDADOS}

\subsection{Shenyang, China}

"Do socioeconomics characteristics affect travel behaviour? A comparative study of low-carbon and non-low-carbon shopping travel in Shenyang CityChina". (LI J.; LO K.; GUO M., 2018).

O estudo em questão tratou do impacto das características socioeconômicas no comportamento individual de viagem na cidade de Shenyang, na China, além de examinar as diferenças entre a escolha do transporte de baixo ou não baixo consumo de carbono para as viagens de compras. A cidade escolhida conta com 42,5\% de seu PIB (Produto Interno Bruto) na indústria terciária, e a maior frequência de deslocamentos ocorre em função do trabalho. Como os transportes, somado a esse setor, são os responsáveis pelas maiores emissões de carbono no país, o objetivo da pesquisa é provar que a diminuição do consumo de energia nos deslocamentos é uma das soluções para a amenização dos efeitos do aquecimento global para a saúde de seus habitantes.

A análise é feita com base em oito centros comerciais da região e seus fluxos tanto nos dias úteis quanto nos finais de semana, por meio de questionários e entrevistas com 1.525 respostas, e dividida em três tópicos: um sobre o comportamento de viagem, como modo de viagem, tempo de viagem, frequência de viagens e rotas de viagem; outro sobre aspectos socioeconômicos pessoais, como propriedade de carro, gênero, idade, educação, ocupação e renda mensal; e um terceiro sobre atitudes em relação ao desenvolvimento do transporte público e suas opiniões sobre compras utilizando carro particular.

Após a coleta dos dados, uma regressão logística binária é formulada como uma equação matemática, com algumas variáveis independentes, e o resultado leva a apenas duas possíveis respostas: transporte de baixo consumo de carbono - bicicleta, bicicleta elétrica, ônibus, metrô e caminhada; e transporte de não-baixo consumo de carbono - veículos privados e táxis.

Uma das premissas, de que os veículos contribuem para o espraiamento das cidades e o aumento da emissão de carbono é confirmada. Assim, as pessoas percorrem maiores viagens para locais em que o meio de transporte usado é 
favorecido, por exemplo vão de carro a shoppings que tenham estradas boas e estacionamento, ou vão de ônibus a locais com muitas linhas; nos locais mais próximos do centro, com menores distâncias, as pessoas usam transportes de baixa emissão. Além disso, há uma forte associação entre o gênero e a escolha do modo de viagem, e entre a renda e o comportamento, ou seja, as mulheres são mais propensas a andar de transporte público, principalmente em dias de mau tempo e em estradas ruins, e quanto maior a renda, maiores são as chances de escolher um meio de transporte de não-baixo consumo de carbono.

Portanto, mesmo que os modos de viagem com baixa emissão de carbono sejam mais frequentes - $80,5 \%$, é importante reduzir a dependência dos veículos privados, melhorar o transporte público e a infraestrutura de serviços não motorizados e desenvolver novos veículos mais limpos e com menor consumo de combustível a fim de reduzir a emissão dos gases de efeito estufa e a polvição ambiental não só em Shenyang, mas em todas as cidades chinesas, onde os mesmos problemas ocorrem frequentemente.

\subsection{Berna - Suíça}

"Shopping travel behaviour: Influencing factors, shopper types and environmental consequences" (Wiese, A; Zielke, S. e; Toporowski,W., 2015).

Este estudo tem como escopo fornecer uma análise quanto ao comportamento de viagem de compra dos consumidores, tendo como foco os efeitos ambientais gerados. De forma mais específica, o objetivo é contribuir para a compreensão profunda dos condutores de comportamento de viagem do consumidor e suas inter-relações. Para tal estudo, fora necessário o entendimento de como os consumidores escolhem os modos de transporte ao planejar suas viagens de compras e os fatores que influenciam no comportamento de viagens de compras e seus efeitos ambientais, como por exemplo, as características sociodemográficas; pessoais e as situações de variações internas e externas.

Como método de pesquisa inseriu-se um questionário elaborado por temas identificados de uma forma consistente e interposta por software, sendo este de análise de dados "Nvivo", e utilizado para estruturar os dados gerados na pesquisa e encontrar possíveis conexões entre o conteúdo das diferentes entrevistas. Faz-se oportuno citar que a entrevista considerou cinco grupos: jovens sem filhos, pessoas com crianças na pré-escolar, pessoas com crianças em idade escolar, idosos com filhos fora de casa ou sem filhos e aposentados. E por fim, a localização residencial, considerando centros de ordem baixa; média e de alta ordem. Levando-se em consideração esses aspectos, os resultados levam a cinco vertentes. Uma delas é a influência do ciclo de vida e psicografia, onde os entrevistados afirmam tentar se comportar de maneira consciente, ponderando sobre questões ambientais diárias, e até mesmo a disposição de usar transporte público com maior frequência. Por outro lado, a influência de fatores externos cogita o impedimento destes ao se utilizar grandes cestas de compras, e aponta a vantagem de usar o carro para maior "flexibilidade". No terceiro tópico, de tipologia dos consumidores, podem-se considerar as palavras-chaves "flexibilidade e conforto" como aspectos mais importantes de comportamento de viagem. Por fim, quanto às expectativas de varejistas e fabricantes de política, a maioria dos entrevistados não são 
adeptos a entregas em domicílio, pois este conceito não é atraente para quem tem o costume de planejar e detalhar suas compras. Conclui-se que os principais aspectos que dificultam 0 uso de transporte público são as avaliações negativas do mesmo, e a necessidade de mobilidade única dos diferentes ciclos de vida.

\subsection{Brisbane - Austrália}

Analysing retail travel behaviour using an Australian data set. (SHOBEIRINEJAD, M.; BURKE, M. e; SIPE, N. ,2012).

O artigo em questão busca analisar o comportamento de viagem para os destinos de varejo em Brisbane, Austrália, usando os dados da Pesquisa de Viagem Domiciliar Sudeste de Queensland (SEQ-HTS). A análise estatística foi realizada para examinar a frequência da viagem, a complexidade da viagem, a escolha do destino e o modo de transporte dos usuários. Na Austrália, os principais tipos de varejo estão localizados nas rodovias, que reforçam o uso do carro. Além disso, o aumento do horário de funcionamento e a ampla distribuição de lojas permitem que as viagens de lazer de uma família variem no tempo de viagem, duração, destino e modo. Os dados de a pesquisa domiciliar de viagens foram fornecidos pelo Departamento de Transporte e Estradas Principais de Queensland. Utilizou-se os dados do Survey Queensland Travel Survey (SEQTS) de 2009, cobrindo viagens de 7 dias de pessoas no sudeste de Queensland, na Austrália. As diferenças foram exploradas entre os dias da semana e fim de semana, homens e mulheres e tipos de mercadorias. Para isSo, a SEQTS utilizou uma amostragem de domicílios. Os formulários foram preenchidos pelos entrevistados com 5 anos ou mais. E cada viagem dos entrevistados foi dividida em "estágios de viagem". Porém, a rota exata percorrida pelos entrevistados não foi capturada no SEQTS. As distâncias de viagem foram calculadas usando SIG para determinar o caminho mais curto na rua e na rede de caminhos. Após a análise de todas as viagens, o conjunto de dados foi manipulado para identificar todas as viagens de varejo feitas, excluindo viagens para comprar gasolina. Esta análise foi feita com a utilização do SPSS (Pacote Estatístico para as Ciências Sociais).

Através dos dados coletados, foi possível confirmar que as viagens de varejo representam uma parte importante em termos da proporção de viagens feitas de carro. Além disso, das viagens de varejo, pouquíssimas são realizadas por bicicleta e/ou táxi. O transporte público, apesar do baixo uso, indentificou-se um aumento de uso durante a semana e uma maior participação de mulheres. Outro dado obtido é de que homens representam a maioria dos motoristas de veículos. Além disso, há uma grande disparidade entre Brisbane interna e externa em termos de uso de transporte sustentável. A explicação disso está no próprio padrão urbano e nas características socioeconômicas dos viajantes. A área interna de Brisbane possui maior densidade de estabelecimentos de varejo e é mais sustentável em termos de uso de meios de transporte ativos (a pé e de bicicleta) em comparação com os subúrbios externos. Observou-se também que entre os principais destinos de compras estão os supermercados e shopping centers, devido à diversidade de mercadorias. E que mantimentos e alimentos são os produtos de compras mais significativos. 
Com isso, nota-se a importância dos shoppings como foco de qualquer tentativa de incentivar um comportamento de viagens de varejo mais sustentável. Além disso, a caminhada e o transporte público ainda são parte importante das viagens de compras para shopping centers e supermercados com base em quão longe a viagem irá. Já as mercearias e lojas de alimentos devem ser estudadas mais de perto. Sendo assim, modificar os hábitos de viagem para esses destinos pode resultar em grandes diferenças no modo de compartilhamento.

\section{ENSAIO SOBRE A CIDADE DE UBERLÂNDIA: ESTUDO PILOTO}

A partir da análise dos estudos comparados nos itens anteriores, foi montada uma metodologia específica, adaptada para a cidade de Uberlândia, MG. Por meio da aplicação de questionários em meio eletrônico, buscou-se identificar os padrões e viagem urbanas voltadas a 4 atividades a saber: a) escola; b) Trabalho; c) Compras de conveniência e; d) Compras esporádicas. Para tal, aplicou-se um estudo piloto composto por uma amostragem preliminar de 100 questionários

O questionário buscou trabalhar com diversas variáveis buscando compreender um amplo espectro da população. Os itens foram: o gênero, a faixa etária, a classificação do núcleo familiar, o valor da renda mensal familiar, o nível de escolaridade, a frequência que se desloca (incluindo viagens para levar filhos ou outras pessoas) da casa até o trabalho, a escola ou instituição de ensino, shopping center, compras de vestuário, supermercado e mercearia (padaria, açougue, sacolão...) que frequenta, o meio de transporte que é utilizado para descolocar até os pontos citados anteriormente, local em que realiza compras de vestuário e mercearia, e por fim, o que influencia a decisão dos locais de compra.

Além disso, o questionário dispunha de uma questão aberta, buscando conhecer o local exato ou alguma proximidade referente ao local de trabalho, escola ou instituição de ensino, shopping center e supermercado frequentado de maneira a poder se estabelecer as distâncias percorridas.

\subsection{Resultados}

Por meio das respostas obtidas diante da amostragem piloto, gerou-se dados tabulados pelo software Qlik, obtendo-se os seguintes níveis de resposta: $68,3 \%$ corresponde ao público feminino; $30,5 \%$ ao masculino e 1,2\% outro. Quanto a faixa etária, o questionário atingiu $0 \%$ dos que apresentariam ter de 0 a 18 anos, seguido por pessoas entre 19 a 29 anos com 57,3\%; de 30 a 50 anos, com $31,7 \%$ e acima de 50 anos, $11 \%$. Mais adiante, os participantes descrevem na pergunta três (3) do questionário qual a classificação de seu grupo familiar, totalizando em $15,9 \%$ sozinho; $11 \%$ monoparental; $57,3 \%$ casal com filhos; $4,9 \%$ casal sem filhos; $8,5 \%$ coabitação sem vínculo afetivo e $2,4 \%$ outros. No quesito renda mensal, $8,5 \%$ apresenta renda até $R \$ 1.000 ; 17,1 \%$ de $R \$ 1.000$ a $R \$ 3.000$; $18,3 \%$ de $R \$ 3.000$ a $R \$ 5.000 ; 28 \%$ de $R \$ 5.000$ a $R \$ 10.000$ e $28 \%$ acima de $\mathrm{R} \$ 10.000$. Sob a mesma ótica analisa-se que diante do nível de escolaridade dos participantes $0 \%$ apresentam apenas ensino fundamental; $18,3 \%$ ensino médio; $57,3 \%$ ensino superior e $24,4 \%$ pós-graduação.

Assim, após a análise e separação dos diversos extratos sociais, a pesquisa avançou para o cruzamento de dados com outros 6 tópicos a saber: trabalho; 
escola; shopping centers; vestuário; supermercado e mercearia, a fim de aplicar os estudos abordados acima. Os dados mostraram, como se pode verificar a partir dos gráficos abaixo, 57,32\% dos entrevistados vão 5 vezes por semana ao trabalho, seguido por $26,83 \%$ dos que nunca vão; $9,76 \%$ frequentam 3 vezes por semana; $2,44 \%$ uma vez por semana ou esporadicamente e 1,22\% uma vez por mês.

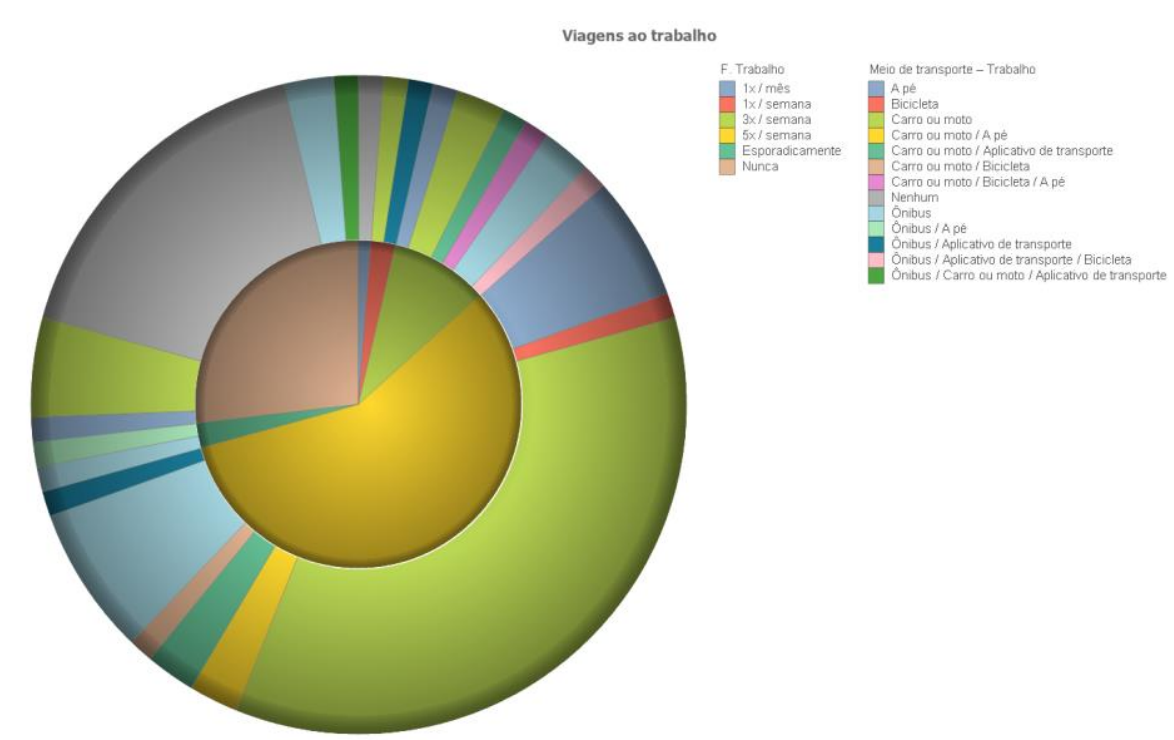

Imagem 1 - Viagens ao Trabalho (Frequência e Meio de Transporte) Fonte: Autores, 2019

De acordo com o mesmo gráfico, apresentado na Imagem 1, carros ou motos são os meios de transporte mais utilizados $(53,66 \%)$, seguido por ônibus $(19,51 \%)$; nenhum (18,29\%); a pé $(13,41 \%)$; aplicativos de transporte $(8,54 \%)$ e bicicleta (4,88\%).

Partindo para a temática de Escola ou Instituição de Ensino, 54,88\% dos entrevistados frequentam 5 vezes por semana, seguido por nunca com 21,95\%; 3 vezes por semana 9,76\%; 1 vez por semana 7,32\%; esporadicamente 4,88\% e 1 vez por mês 1,22\%, como demonstra a Imagem 2, localizada abaixo.

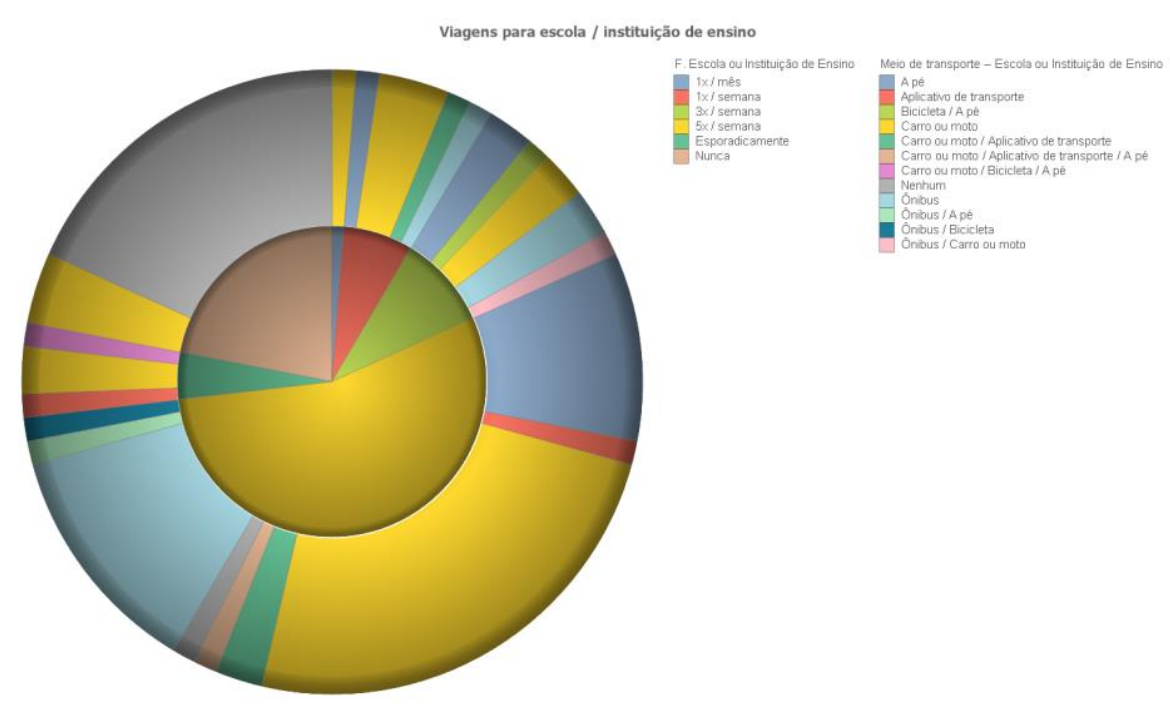




\section{Imagem 2 - Viagens à Escola ou Instituição de Ensino (Frequência e Meio de Transporte)}

Fonte: Autores, 2019.

Neste caso, os meios de transportes mais utilizados permanecem sendo carros ou motos, com 45,12\%; seguido de ônibus, a pé e nenhum com 19,51\%; aplicativos $(7,32 \%)$ e bicicleta $(3,66 \%)$.

O terceiro tópico, que se refere ao Shopping Center, $48,78 \%$ dos entrevistados frequentam esporadicamente; $23,17 \%$ vão 1 vez por mês; seguido por $20,73 \%$ que vão 1 vez por semana; 3,66\% frequentam 3 vezes por semana; $2,44 \%$ que nunca vão e $1,22 \%$ vão 5 vezes por semana.

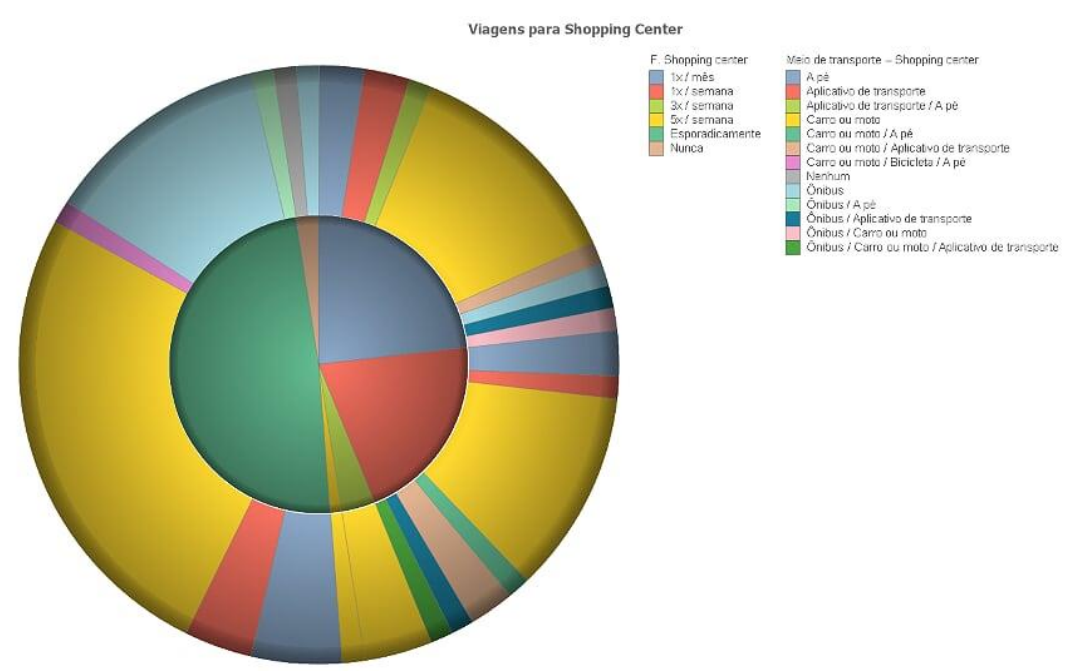

Imagem 3 - Viagens ao Shopping Center (Frequência e Meio de Transporte) Fonte: Autores, 2019.

De acordo com o gráfico acima, Imagem 3, carros ou motos são os meios de transporte mais utilizados $(62,20 \%)$, seguido por ônibus $(20,73 \%)$; aplicativos de transporte e a pé $(15,85)$ e bicicleta e nenhum $(1,22 \%)$.

Já no próximo tópico compras de vestuário, $67,07 \%$ dos entrevistados frequentam esporadicamente, seguido por 1 vez por mês com 26,83\%; 1 vez por semana $3,66 \%$ e nunca com $2,44 \%$ como demonstra a Imagem 4, localizada abaixo. 


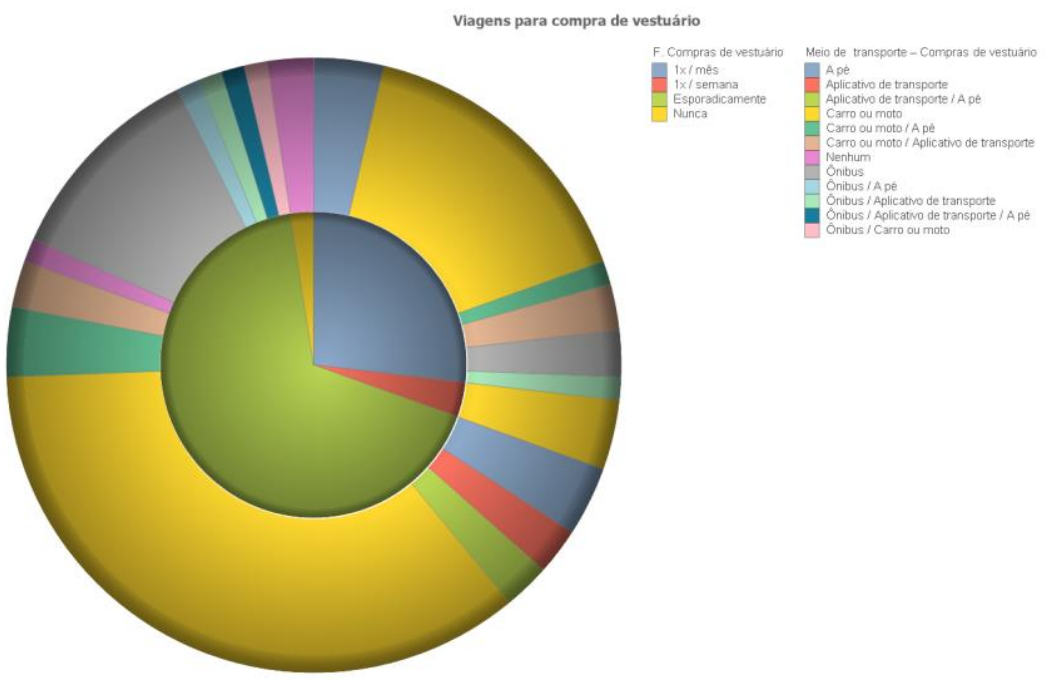

Imagem 4 - Viagens a compras de vestuário (Frequência e Meio de Transporte) Fonte: Autores, 2019.

Neste caso, os meios de transportes mais utilizados permanecem sendo carros ou motos, com $65,85 \%$; seguido de ônibus $(20,73 \%)$; a pé $(17,07 \%)$; aplicativos $(13,41 \%)$ e nenhum com $(3,66 \%)$.

No quinto tópico, tendo como referência os Supermercados, $6,10 \%$ dos entrevistados vão 5 vezes por semana; seguido por 1,22\% dos que nunca vão; $14,63 \%$ frequentam 3 vezes por semana; $39,02 \%$ uma vez por semana ou esporadicamente e $28,05 \%$ uma vez por mês.

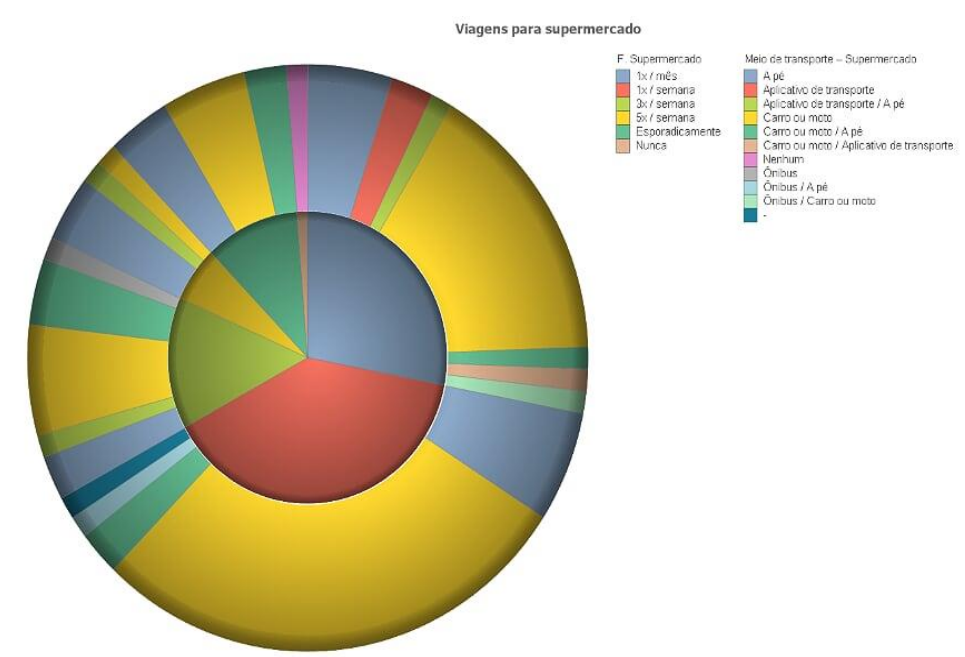

Imagem 5 - Viagens à Supermercado (Frequência e Meio de Transporte)

Fonte: Autores, 2019.

De acordo com o mesmo gráfico, apresentado na Imagem 5, carros ou motos são os meios de transporte mais utilizados $(68,29 \%)$, seguido por a pé $(37,80 \%)$; nenhum (18,29\%); aplicativos de transporte (7,32\%); ônibus $(3,66 \%)$ e nenhum $(1,22 \%)$.

No sexto, e último tópico, a temática tratada é Mercearia. 13,41\% dos entrevistados frequentam 5 vezes por semana, seguido por nunca com 1,22\%; 3 vezes por semana $25,61 \%$; 1 vez por semana 35,37\%; esporadicamente $15,85 \%$ e 1 vez por mês 8,54\%, como demonstra a Imagem 6, localizada abaixo. 


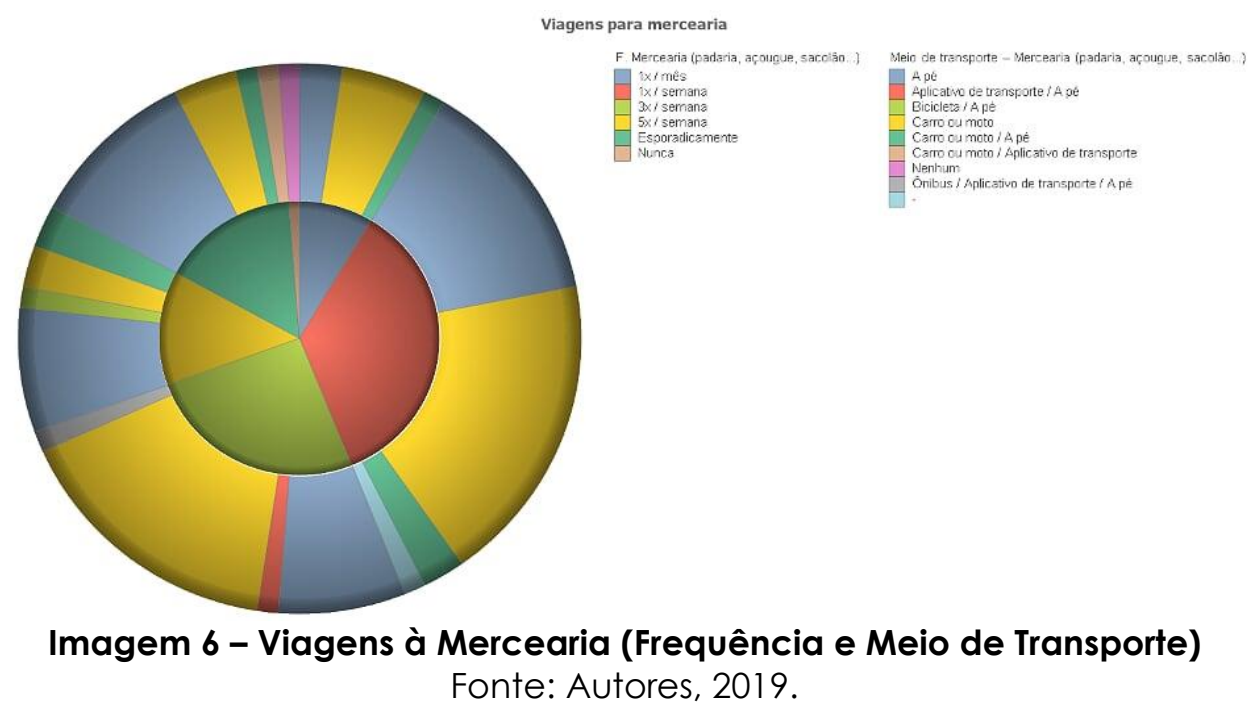

Neste caso, os meios de transportes mais utilizados são carros ou motos, com $53,66 \%$ e a pé, também com 53,66\%; seguidos aplicativos (3,66\%); ônibus, bicicleta e nenhum com $1,22 \%$.

\subsection{Discussão}

A partir dos dados preliminares, podem-se perceber os seguintes padrões:

a) As viagens diárias são majoritariamente motivadas pelo trabalho e atividades de Educação. A maior parte dos respondentes realiza 10 ou mais viagens por semana com essa finalidade.

b) O número de viagens semanais vai diminuindo conforme o tipo de estabelecimento, sendo maior naqueles de conveniência; Mercearias, açougues ou padarias recebem em média 3 visitas semanais, seguidas por supermercados, com 1 visita semanal e shopping centers com menos de 1 visita no mesmo período.

c) Em todos os tipos de viagens, é possível notar a prevalência dos modais motorizados, presentes em mais de $50 \%$ das viagens para todas as classes de renda. Também é possível avaliar a pouca utilização de transportes coletivos, que em nenhum quesito ultrapassou os $20 \%$.

d) No tópico Mercearia é possível identificar um grande aumento de pessoas que frequentam a pé, uma vez que estes estabelecimentos costumam ser próximos de suas residências.

d) Os transportes por aplicativo apareceram em posição de ascensão, registrando participação de até $15 \%$ e superando o transporte coletivo no caso de modal utilizado para ir ao Shopping Center.

Embora preliminares, os números permitem aferir que há um padrão de transportes bem definido em Uberlândia, configurados em torno das viagens ao trabalho ou escola e majoritariamente feitas por meio de veículos motorizados. O sistema continua pendular com o porte da mancha urbana permitindo a ida para almoço e casa. A partir dessa relação casatrabalho/escola, se organizam as outras viagens observando-se que a diminuição das distâncias e o aumento da frequência para as compras de conveniência denota uma mobilidade travada que leva ao padrão de comprar em estabelecimentos no caminho da casa para o trabalho/escola. A 
baixa utilização do sistema de transportes coletivos, faz evidente a falta de competitividade desse modal com outros, com especial destaque para a emergência dos transportes por aplicativo cujos custos, se utilizados por mais de 3 pessoas no mesmo veículo, acabam por serem na média mais baratas do que a tarifa dos ônibus.

\section{CONSIDERAÇÕES FINAIS}

Os trabalhos analisados nos permitem concluir que há diversas variáveis na definição dos padrões de viagem da população com peculiaridades conforme sua região geográfica, aspectos socioeconômicos e culturais e ainda a idade. Os estudos deixam mais clara a prevalência do uso do automóvel como meio de transporte para as compras, independente do continente estudado. No caso de Uberlândia, a utilização de transportes motorizados tem taxas ainda inferiores aos estudos de caso analisados em outros países. No entanto, atinge índices crescentes, ainda mais alarmante quando não se observam políticas públicas para a ampliação da mobilidade via modais mais sustentáveis. O presente estudo se beneficiará do aumento da amostragem a ser efetivado após os ajustes no questionário piloto. Também contará com uma sensível contribuição às análises a partir da tabulação das distâncias percorridas e do cruzamento com os dados do uso do solo, ambos a serem elaborados na próxima etapa, quando novas ferramentas devem ser incorporadas como sensores e aplicativos computacionais para 0 processamento de Big Data, a fim de se obter maior eficácia no cruzamento e processamento de um número grande, mais relevante de informações.

\section{AGRADECIMENTOS}

Ao CNPq e à Fapemig pelo apoio recebido.

\section{REFERÊNCIAS}

Clarke, M. Big Data in Transport. The Institution Of Engineering and Technology (IET). London, 2016.

LI J.; LO K.; GUO M. Do socioeconomics characteristics affect travel behaviour? A comparative study of low-carbon and non-low-carbon shopping travel in Shenyang City-China. International Journal of Environmental Research and Public Health, 2018.

LIMANOND, T. \& NIEMEIER, D. A. Effect of land use on decisions of shopping tour generation: A case study of three traditional neighborhoods in WA.

Transportation, 31, 2004, pp.153-181.

SHOBEIRINEJAD, M.; BURKE, M. e; SIPE, N. Analysing retail travel behaviour

using an Australian data set. Australian Transport Research Forum, 2012

Proceedings. Disponível em:

<https://core.ac.uk/download/pdf/143869843.pdf>. Acesso em: 20 set 2018

THE URBAN TRANSPORT INSTITUTE, T. South-East Queensland Travel Survey 2009. Queensland Transport and Main Roads. 2009.

WIESE, A; ZIELKE, S. e; TOPOROWSKI, W. "Shopping travel behaviour: Influencing factors, shopper types and environmental consequences", International Journal of Retail \& Distribution Management, Vol. 43 Iss: 4/5,2013, pp.469-484. 